\title{
A Survey on the Outsourcing of Cataloging in Academic Libraries
}

\author{
Katherine A. Libby and Dana M. Caudle
}

The authors conducted a survey on outsourcing of cataloging in academic libraries in order to determine the extent of outsourcing being done in academic libraries and the overall success of such projects. The survey instrument included questions about factors that might affect the decision to outsource, what reasons libraries had for outsourcing or not outsourcing, what was being outsourced, and how vendors were chosen. Libraries were also asked to evaluate the success of outsourcing projects. The results show that outsourcing of cataloging is not a strong trend in academic libraries, but that libraries which outsourced were generally pleased with results. There also seems to be a correlation between size of collection and number of new titles cataloged annually and the decision to outsource.

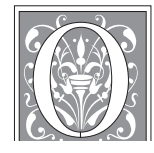

utsourcing has been a hot topic in cataloging circles in the last decade, especially since the Wright State University library made its controversial decision to outsource all of its cataloging operations to OCLC TechPro in 1993. This sparked many heated discussions regarding the value and quality of outsourced cataloging, as well as many articles describing outsourced projects. However, no one has determined the extent to which academic libraries actually outsource cataloging or the overall success of these endeavors. Therefore, we decided it would be both interesting and appropriate to conduct a survey to address these issues. Claire-Lise
Benaud and Sever Bordeianu of the University of New Mexico are also researching outsourcing in academic libraries and include several general questions on outsourcing of cataloging in their recent survey. Because our survey focuses on cataloging in greater detail and includes an assessment of the results of outsourcing projects, our results should complement, rather than duplicate, their effort.

\section{Literature Review}

The literature review mainly covers the literature published in the 1990's, since little was published on outsourcing in the 1980's (a finding borne out by the comprehensive literature review on outsourcing

Katherine A. Libby is Catalog Librarian at Sherrod Library at East Tennessee State University; e-mail: libby@access.etsu-tn.edu. Dana M. Caudle is Science/Technology Cataloger at Auburn University Libraries; e-mail: dcaudle@lib.auburn.edu 
in an article by Karen A. Wilson). ${ }^{1}$ Also, cataloging technology and methods have changed too much for earlier articles to be germane. This review is not a comprehensive survey of the topic. Rather it includes representative pieces. We found three basic types of materials: general writings on outsourcing, descriptions of outsourcing services offered by various vendors, and accounts of outsourcing projects at specific libraries.

\section{General Writings}

The first of the general writings is the pamphlet Outsourcing Cataloging, Authority Work and Physical Processing: A Checklist of Considerations, issued by the Commercial Technical Services Committee of ALCTS. ${ }^{2}$ This is a comprehensive guide on how to plan an outsourcing project which outlines what questions should be asked to determine if outsourcing is the best course of action for a library. It also includes further questions and checklists on which tasks will remain with the library if they outsource, how to choose a contractor, what information the contractor will need to process the library's materials, what type of materials the library plans to outsource, the cataloging standards to be adhered to, authority work, the form of output the contractor is to provide, physical processing, and financial considerations. There is also an excellent, if brief, bibliography of recent outsourcing literature.

Carlen Ruschoff discusses recent trends in libraries and how they affect cataloging. ${ }^{3}$ He gives a number of options for responding to the four major "forces" affecting libraries, including streamlining procedures, simplifying cataloging standards, cooperative cataloging, contract cataloging, and expert systems for cataloging. The analysis of each of these points is both cogent and interesting, but for the focus of this article, we will limit ourselves to summarizing his comments on contract cataloging, or outsourcing. There are two basic reactions among catalogers to the notion of outsourcing. One is the negative reaction: the concern that outsourcing will lead to loss of local cataloging expertise, damage cooperative cataloging efforts, and cause a degradation in the quality of new cataloging records. Other facets of this reaction are the fears that, in an effort to keep costs down, vendors will not hire professional catalogers and that vendors may impose proprietary restrictions on the sharing of records. The positive reaction is that, with outsourcing, professional catalogers will be able to devote their time to tasks requiring their expertise. Ruschoff concludes that "contract cataloging... may prove a cost-saving alternative to processing titles within the library. Its effectiveness depends upon the unique needs and special circumstances within each library" ${ }^{4}$ and points out that these needs and circumstances should be considered in planning to outsource.

In a similar vein, Daniel CannCasciato wrote an article prompted by reactions to OCLC's unveiling of PromptCat and a similar service called InfoSmart in 1993, and to an Autocat discussion regarding Wright State University's announcement that they were outsourcing all their cataloging operations. ${ }^{5}$ The general reaction in both cases was much alike: concern that the role of catalogers and cataloging departments would be reduced, and that the quality of cataloging would diminish. CannCasciato admits that both of these results are possible, but states that it is up to catalogers to take the lead and prevent it. Outsourcing can provide an opportunity for catalogers to spend their time on original cataloging, participate in national-level authority work, enhance existing records, and other such activities. Commercial cataloging agencies would 
not be economically feasible without the existence of major databases of cataloging records, such as the OCLC online union catalog, and plenty of catalogers to contribute to and maintain them. CannCasciato also maintains that one of the advantages in the current system is the depth and breadth of expertise in cataloging. Libraries are not in the business of making money; if all operations were looked at from the viewpoint of financial solvency, he asks, what would happen to labor-intensive cooperative projects such as NACO?

Rick J. Block examines issues to be considered before outsourcing from the perspective of a retrospective conversion project at Tufts University which had disappointing results. ${ }^{6}$ Block points out that outsourcing is not necessarily a bad thing, only that it should be carefully evaluated. Outsourcing of approval plan items, special and archival collections, large uncataloged backlogs, and other projects could certainly enhance a library's mission. He cautions that libraries which choose to outsource all or part of cataloging should carefully consider such factors as the real cost of cataloging, the impact on users and database quality, ease of rush processing, system implications, workflow, size and content of backlogs, turnaround time, and staff skills assessment before making their decision. Libraries which eliminate cataloging entirely risk giving up staff with valuable skills in organization of knowledge which might be needed in the future. ${ }^{7}$ They also risk losing local bibliographic control, flexibility, and historical perspective. Finally, libraries which decide to outsource everything will have a hard time either restoring their cataloging department or changing vendors.

Clare B. Dunkle compares the current discussion of outsourcing of cataloging to the recent business trend of outsourcing information systems, citing business literature on outsourcing over the past few years, as well as library literature, to support her case. ${ }^{8}$ If it is planned carefully, outsourcing can be a good solution, while if it is gone about carelessly, it can be a spectacular failure. Dunkle addresses a number of assumptions that are made about outsourcing: that it will save money, that vendors will use the most current technology, that outsourcing leads to greater flexibility for the outsourcing institution, and that the vendor will provide a high-quality product without being specifically instructed to do so. In her discussion, she points out the fallacies and pitfalls of these assumptions, and outlines what is needed for successful outsourcing. This boils down to careful planning and contract negotiation, including determining exactly what the tasks to be outsourced involve to ensure that the vendor really can provide better service, working with the vendor to make sure that all the performance goals and guidelines are clearly understood, and continuing to monitor the vendor to make sure that they are being met. Dunkle then asks the big question of why outsource at all. One of the common rationales for outsourcing is that the activity being outsourced is a "non-core" activity to the mission of the institution. Arnold Hirshon used this argument in discussing Wright State's reasons for outsourcing cataloging, although Dunkle questions his assertion that it is possible for the output of a technical services department (cataloging records and processed books) to be core if the activity to create the output is not. Another reason is to remove a perceived problem from an institution. Dunkle maintains that managers who do not understand cataloging will be more likely to outsource it, especially if there are communication problems between the catalogers and managers, or personnel and productivity problems in the cataloging department. While 
outsourcing selectively is an option for most libraries, total outsourcing is probably not feasible for many. Dunkle adds that "in-house cataloging departments have the opportunity to develop unique solutions for local users, and some of these unique solutions become the new state of the art.... In-house catalogers and library vendors must work in a symbiosis to bring about change." 9

Magda El-Sherbini and Mary Harris report in detail on an Ohio State University Libraries Ad Hoc Task Force which examined the advantages and disadvantages of cataloging done outside the cataloging department. ${ }^{10}$ One option was the use of commercial vendors. In dealing with a vendor, the library must spell out goals for outsourcing and determine exactly what it wants done. Pricing structure can be complex, so libraries need to study the nature of the collection to determine if per item or per hour charges are cheaper. El-Sherbini and Harris also discuss requirements for vendors, such as whether the vendor has appropriate staff and access to OCLC or RLIN. Libraries should seek proposals from several vendors to compare price and quality, and should also obtain opinions of vendors from other institutions. Problems include finding a vendor that can accomplish the task, the expense of commercial cataloging, lack of guarantee about quality, and cataloging unresponsive to the needs of the end user. El-Sherbini and Harris conclude that outsourcing might be appropriate for a small collection that does not require difficult cataloging or a library with a small staff. ${ }^{11}$

\section{Vendor Services}

There are several articles about outsourcing services provided by bibliographic utilities. Cynthia Whitacre details the workings of OCLC's TechPro service, including customization options for the contract, the determination of pricing, acceptable surrogates for materials, and methods of quality control. ${ }^{12}$ While TechPro would certainly be happy to handle all of a library's cataloging operations, outsourcing is not for every library. ${ }^{13}$ TechPro intends to focus on large academic or public libraries with backlogs or special groups of materials such as audiovisual or foreign language materials. Jim Dwyer describes the PromptCat service currently offered by OCLC. ${ }^{14}$ With PromptCat, vendors send approval lists electronically to OCLC and OCLC sends the matching MARC record to the libraries via electronic data transfer or tape. PromptCat's "fatal flaw" is the large number (50\% to $80 \%$ ) of incomplete CIP records. ${ }^{15}$ This is not as much of a problem as it once was, thanks to the collaboration of OCLC and Yankee Book Peddler to establish a CIP upgrade service. ${ }^{16}$ David Griffin describes the WLN cataloging service, focusing on its treatment of serials. ${ }^{17}$

Gary M. Shirk examined outsourcing of technical services from a vendor's perspective. ${ }^{18} \mathrm{He}$ observes that vendors view technical services as a logical extension of their relationship with libraries and provision of outsourcing for those services as an opportunity to strengthen that relationship. ${ }^{19}$

Carmel C. Bush, Margo Sasse, and Patricia Smith survey the capabilities of different vendors to provide outsourcing for acquisitions, cataloging, and collection development. ${ }^{20}$ After presenting detailed findings on the type of cataloging offered by materials jobbers, contract cataloging agencies, and library consortia, they reach several conclusions. Materials jobbers and library consortia can supply timely cataloging for mainstream materials, but are less likely to offer special services like customized classification. Contract cataloging agencies such as bibliographic utilities and private companies offer more 
complete services including original cataloging, customized classification, and cataloging of foreign language materials.

\section{Outsourcing Projects}

The remaining articles in this literature survey consist of descriptions of various outsourcing projects. Two focus on the situation at Wright State University. Karen Wilhoit describes Wright State University's decision to outsource its cataloging operation and the result. ${ }^{21}$ Wright State discovered that they could save significant money by outsourcing and deal with problems such as an unproductive staff, a backlog of 5000 items, an uneven workload, and the lack of original cataloging being done. In 1993, they issued a request for proposal and hired OCLC TechPro to handle all cataloging operations. Wilhoit considers the operation to be a success in terms of reduced cost and turnaround time without loss of quality. Barbara A. Winters' article complements Wilhoit's description of how Wright State arrived at its decision and implemented it. ${ }^{22}$ Wright State realized definite savings in the cost of cataloging and achieved much quicker delivery of materials to patrons. Winters believes that in the future, mundane cataloging will be outsourced, while professionals will manage and evaluate cataloging contracts.

Karen A. Wilson wrote a detailed discussion of an outsourcing project at Stanford University's J. Hugh Jackson Library. ${ }^{23}$ The library's management had several goals in mind for this project, including consolidating as many purchases as possible to one major vendor, acquiring shelf-ready materials with complete cataloging and physical processing from that vendor, maintaining high quality in cataloging and physical processing of outsourced materials, reducing technical services costs, and reallocating technical services personnel to public services.. Stanford chose Blackwell North America (BNA) and B.H. Blackwell Ltd. (BHB) as their primary vendors and limited the outsourcing activity to Library of Congress copy cataloging and physical processing of monographs. For the initial period of one year for BNA material and four months for $\mathrm{BHB}$, the library received new materials and cataloging records, fine-tuned procedures, and kept careful records of the results of their outsourcing. After an initial shake-down period, the quality of records received was consistently high. Stanford eventually decided that materials with CIP records would be cataloged in-house, because of the large number of CIP records that had to be edited locally. The library was pleased with the success of the pilot project, and has continued to use BNA's and BHB's outsourcing services.

Colleen F. Hyslop describes the implementation of PromptCat at Michigan State University. ${ }^{24}$ The library now sends 90 percent of its approval plan items straight from acquisitions to labeling, with acquisitions handling any needed CIP upgrade. ${ }^{25}$ Hyslop feels that PromptCat is a great tool for enhancing cataloging productivity, so that copy catalogers can do more complex materials and original cataloging.

Magda El-Sherbini reports on Ohio State University Libraries' pilot project to outsource cataloging of Slavic language books. ${ }^{26}$ The goals were to test the quality of records obtained from the vendor (OCLC TechPro) and determine the cost for in-house cataloging versus outsourcing. El-Sherbini described at length the methods used to determine quality and cost of cataloging. Contract cataloging turns out to be a viable method, with acceptable cataloging at a lower cost. ${ }^{27}$

Laura Tull describes the outsourcing of retrospective conversion for a technical 
report collection at Texas A\&M. ${ }^{28}$ After stressing the importance of a good contract for telling the contractor what to do and for maintaining quality control, Tull details the provisions of the Texas A\&M contract, such as procedures for determining a match on OCLC, what fields to edit, what authority was needed, and problems to be returned. The main advantage to outsourced retrospective conversion is the speed with which a large volume of material can be cataloged, but this is offset by the decline of quality. ${ }^{29}$

Karen Dornseif offers an interesting perspective in her article on the outsourcing project at the Larimer Campus of the Front Range Community College in Fort Collins, Colorado. ${ }^{30}$ The library there employs only one full-time librarian, and two part-time temporary library assistants. Larimer had depended on a part-time cataloger at another campus to catalog their materials, but a backlog had built up, and had to be eliminated. The librarian went to a cataloging training session at the Bibliographical Center for Research (BCR), and realized that in-house cataloging was not feasible for her library. Larimer contracted with BCR to catalog the backlog, then decided to continue the contract for new acquisitions. Outsourcing has worked well for Larimer, which is receiving good quality records at a reasonable cost. There have been a few problems, which were quickly resolved. One disadvantage is the lack of local control over cataloging. An in-house cataloger could get materials on hot topics to users more quickly, and could add additional subject headings for local use. Records are sometimes loaded into CARL, the on-line catalog, up to two weeks before materials can be shelved. There is no local authority control, and BCR does not add Larimer's holdings to OCLC. Dornseif concludes that "while outsourcing is not the perfect cataloging solution..., it is the only one that allows the library to maintain a current automated catalog... and provide the services expected...." ${ }^{31}$

Karen A. Wilson summarizes the discussion from an ALCTS meeting on outsourcing at ALA Midwinter in 1994. ${ }^{32}$ Some participants reported problems in dealing with item records and barcodes, access points, authority control, database maintenance, and workflow. Large universities got faster and less expensive cataloging while those with a low volume experienced the same or greater turnaround time. ${ }^{33}$ The meeting ended with a discussion of the impact of outsourcing on OCLC and RLIN and a call for vendors to supply full-level MARC records.

As we examined the literature, some common themes emerged. One was the need to carefully consider the goals of outsourcing, and how they will be met by the vendor. Another theme is the need for careful planning.

\section{Survey Instrument}

Keeping these themes in mind, we formulated the survey questions. The survey focused on whether academic libraries were outsourcing, the reasons for their decisions, and an evaluation of the outsourcing project, especially whether the library in question would outsource choose to again. We also considered a number of factors that might affect whether a library chose to outsource cataloging, such as size of collection, staffing levels, and amount of new material received annually. The rest of the questions concerned other factors that would affect the success of an outsourcing project such as type of materials to be outsourced, choice of vendor, and the amount of planning that went into the process.

In order to choose the institutions to receive surveys, we compiled a list of academic libraries in the United States 
from the American Library Directory ${ }^{34}$ and picked every tenth library. Any library, including medical and law libraries, located on the campus of an educational institution that offered a bachelor's degree or higher qualified as an academic library. We did not include branch libraries lacking cataloging departments, on the assumption that cataloging was done in the main library. The survey was mailed to 187 libraries in January of 1997, with a request that responses be returned by March 15, 1997. Each survey packet provided postage paid return envelopes, in order to ensure the anonymity of the respondents. Of the 187 surveys sent, we received 117 replies, a return rate of $63 \%$.

\section{Results}

Of the 117 responses received, thirtythree respondents (28\%) said they were currently outsourcing, or had outsourced in the past. The remaining eighty-four respondents $(72 \%)$, however, said they had never outsourced cataloging. Clearly, outsourcing of cataloging is not a prevailing trend among academic libraries. In an attempt to determine some of the conditions that might influence a library's decision to outsource, we conducted ttest analyses with all libraries that had outsourced at any time in one class, and those that had not in a second. Each ttest used one of the following variables: size of collection, number of professional librarians in the cataloging department, number of paraprofessional staff in the cataloging department, and number of new titles received annually. All statistical tests were conducted at a $95 \%$ confidence level. Because some libraries did not provide data for all questions, degrees of freedom on the t-tests varied from 109 to 115. We obtained the expected $t$-value of 1.980 for each of the test using a standard table, in which 120 degrees of freedom was the closest value.
The first t-test tested the null hypothesis that there is no correlation between the size of collection and the decision to outsource. The t-test yielded a t-value of 2.424. Since the observed t-value is greater than the expected $t$-value, the null hypothesis should be rejected. This suggests that there is, in fact, a correlation between the size of the collection and the decision to outsource. The second t-test examined the null hypothesis that there is no correlation between the number of professional librarians and the decision to outsource. The t-test result of 1.614 is less than the expected value. Therefore, we concluded that the null hypothesis is true, and there is no correlation between the number of professional librarians and the decision to outsource. For the third t-test, the null hypothesis stated that there is no correlation between the number of paraprofessional staff and the decision to outsource. The t-test yielded an observed $t$-value of 1.620 , which is again less than the expected value. Thus, the null hypothesis should be accepted as true. The final t-test null hypothesis that there is no correlation between the number of titles received annually and the decision to outsource produced a $\mathrm{t}$-value of 3.352. This is greater than the expected value, so the null hypothesis is false. There is a correlation between the number of titles received and the decision to outsource. While staffing levels evidently have no effect on the decision to outsource, size of collection and the number of new titles received annually apparently do. The mean collection size of the libraries that outsource is 606,330 volumes as opposed to 311,238 for those that do not. The mean number of new titles received annually for libraries that outsource is 13,786 , versus 5,751 for those that do not. It appears from these statistics, along with the results of the t-tests, that libraries with larger collections and 


\section{A Survey on the Outsourcing of Cataloging in Academic Libraries 557}

larger numbers of incoming titles are more likely to outsource.

In the following sections of the report, the percentages of answers for some of the questions add up to more than $100 \%$ because some libraries chose more than one option to answer the questions. We decided to break them out into individual answers instead of trying to detail all possible combinations.

Of the eighty-four libraries that have not outsourced cataloging, fifty-two (62\%) have never considered outsourcing, sixteen $(19 \%)$ are currently considering outsourcing, and eighteen (21\%) considered outsourcing in the past but decided against it. We chose to count two libraries in both categories of consideration, because they provided data on a past rejection of outsourcing and a current reconsideration. Among those libraries which considered outsourcing but decided against it, six (33\%) thought it would be too expensive, twelve $(66 \%)$ thought it would not be cost-effective, and seven (39\%) gave other reasons. One reason mentioned was concern about mistakes in and/or upgrading of CIP records. Several libraries thought that vendors would be unable to accommodate highly specialized materials or local cataloging practices, such as multiple classification systems, additional tracings required locally, and multiple shelving locations. Concern about turn-around time were also a factor for some. In other libraries, there was simply local opposition to the practice, as in the case of one consortium member when the other libraries did not want non-LC records added to their shared database. One library commented that they felt it would be too complicated; another agreed and further categorized outsourcing as "an unnecessary luxury item." Yet another library stated that they never felt the need.

Currently sixteen libraries are considering outsourcing a variety of materials.
Four (25\%) want to outsource all cataloging operations, together with physical processing and authority control, while four others $(25 \%)$ want to outsource retrospective conversion. Ten libraries (63\%) seek to outsource special types of materials. These materials include approval plan items, Library of Congress or other copy cataloging, government documents, foreign language materials (Japanese was specifically mentioned), videos and other audiovisual materials, and special collections materials. Another five libraries $(31 \%)$ are interested in outsourcing short-term special projects such as gift collections and backlogs. One library wishes to conduct a test of fifty titles to evaluate the feasibility of future outsourcing projects.

The thirty-three libraries that have outsourced cataloging gave a variety of reasons for doing so. An overwhelming majority of twenty-three libraries (70\%) said that they had insufficient staff to complete the task in a timely manner. This seems to support our previous statement that libraries with larger workloads, as evidenced by collection size and number of new titles received, tend to be more likely to outsource. Seven libraries (21\%) lacked the in-house expertise needed to complete the task. Ten others (30\%) thought it would be less expensive than doing the task in-house. Three libraries (9\%) felt that outsourcing would be faster. The last library's administration made the decision for them.

We asked each library how carefully they evaluated the need to outsource before committing to their projects. Of the thirty responses to this question, fourteen libraries (47\%) said they carefully evaluated the need to outsource, thirteen ( $43 \%$ ) said they thought it sounded feasible but didn't do an extensive study, and three $(15 \%)$ did not evaluate at all because of time constraints. 
The libraries went through a variety of processes to choose their vendors. Five (15\%) issued a request for proposal followed by a bid process. Another sixteen (48\%) chose their vendor based on reputation, while seventeen (52\%) had had other dealings with their vendor. Four (12\%) gave other reasons. One was a law library who contracted with its parent institution. One checked another vendor and consulted with other institutions about their choice of vendors. One respondent said the decision had been made previously. At the last institution, the library administration made the choice. Libraries primarily chose OCLC (both TechPro and PromptCat), Marcive, and Baker and Taylor, with OCLC being the clearest preference. Other vendors includes TALX, AMIGOS, BNA, Yankee Book Peddler, LTI, Brodart, McSorley, CAPCOM, Professional Media, and two consortia, the Cooperative College Library Center and the Pittsburgh Regional Library Center.

These libraries are outsourcing a wide range of materials. Six (18\%) are outsourcing all cataloging operations, including physical processing and authority control. Fifteen (45\%) outsource retrospective conversion. Some of the fourteen (42\%) who outsource special types of materials chose such things as approval plan materials, National Library of Medicine or Library of Congress records, and original cataloging. Others outsource government documents, foreign language materials (especially Asian languages), videos and audiovisual materials, and theses and dissertations. One library receives vendor-supplied cataloging for a portion of its acquisitions. Five library (15\%) outsource special projects such as backlogs, including gift items, foreign language materials, and upgrades to minimal cataloging records. One is outsourcing some monographic cataloging and physical processing as a short-term experiment.
Each library evaluated the success of its outsourcing project. When asked if outsourcing provided the desired result, seventeen (52\%) said yes, twelve (36\%) said not entirely, and four (12\%) said no. The libraries also rated their experience with six $(19 \%)$ excellent, eleven (34\%) good, eight $(25 \%)$ satisfactory, three $(9 \%)$ fair, and four $(13 \%)$ unsatisfactory response. This suggests that, while not all libraries were completely satisfied, on the whole outsourcing is a positive experience. In fact, of the libraries that outsourced, fifteen $(47 \%)$ will definitely continue to outsource and seventeen (53\%) would consider outsourcing again, depending on the project. On library chose not to answer the question. None categorically refused to consider it again.

The sixteen libraries which were not entirely satisfied or dissatisfied with the results of outsourcing gave one or more reasons for their rating. These broke down as follows: three (19\%) said that insufficient planning went into the process, twelve $(75 \%)$ cited poor customer service from the vendor, two (13\%) said the process did not save the money they expected, and four $(25 \%)$ said the vendor was unable to deliver services as promised. Ten libraries (63\%) gave other reasons. Most of these reasons involved cataloging errors such as incomplete or inaccurate records, wrong records, inability to deal with National Library of Medicine Classification and Medical Subject Headings, inability to deal with multiple shelving locations, and errors in physical processing. Several libraries felt that the process was too slow. Two libraries were satisfied with quality, but one said the vendor could only handle one third of their purchases and the other, whose goal was outsourcing all cataloging, still had to perform some original cataloging themselves.

We performed three chi-square tests at 95 percent confidence level to determine 
what factors might influence the result of an outsourcing project. For the first factor, the null hypothesis stated that there is no correlation between the type of material outsourced and the result of outsourcing. With fourteen degrees of freedom, the chisquare value was 16.173 , which is less than the expected chi-square value of 23.685 , leading us to accept the null hypothesis. The next factor was the evaluation process before starting the outsourcing project. Again, the null hypothesis stated that there is no correlation between the amount of evaluation performed and the result of the project. The chi-square value of 8.247 with four degrees of freedom is less than the expected value of 9.488 . Thus the null hypothesis is true. Finally, we tested the null hypothesis that there is no correlation between the method used to choose the vendor and the result of outsourcing. We obtained a chi-square value of 10.979 with twelve degrees of freedom, which is less than the expected value of 21.026. Again, we accept the null hypothesis. Apparently, none of these factors affect the results of outsourcing projects. However, with only thirty-three outsourcing libraries responding, the survey sample may not be large enough to yield valid results.

\section{Conclusions}

Outsourcing doe snot seem to be a strong trend in academic libraries. Out of 117 libraries who responded, only thirty-three libraries have outsourced at all and sixteen more are considering it. The majority of libraries (fifty-two) have never outsourced and never considered it, while another eighteen had decided against it in the past. The t-tests indicate that size of collection and number of new titles received annually seem to affect the decision to outsource. Of the thirty-three libraries which outsource, most seem to be generally pleased with the experience. Regardless of the quality of that experience, no one refused to consider outsourcing again. Slightly over half said they would consider it depending on the project. While we could not reliably determine from our sample whether factors such as the amount of planning, method of choosing the vendor, and type of materials outsourced affect the results, the chi-square tests seem to indicate that they do not. Further research on a larger sample may shed some light on this. Another option for further research might be to conduct a similar survey among all types of libraries to see if certain types of libraries tend to outsource more than others and how successfully they do so. Our survey should have included other considerations, such as the reasons libraries considering outsourcing thought to do so, what quality control measures were used by libraries that did outsource, and whether the libraries in question were automated. Future researchers may wish to consider these aspects.

\section{Notes}

1. Karen A. Wilson, "Outsourcing Copy Cataloging and Physical Processing: A Review of Blackwell's Outsourcing Services for the J. Hugh Jackson Library at Stanford University," Library Resource and Technical Services 39, no. 4 (1995): 359-383.

2. Association for Library Collections and Technical Services. Commercial Technical Services Committee, Outsourcing Cataloging, Authority Work, and Physical Processing: A Checklist of Consideratons, ed. Marie A. Kascus and Dawn Hale (Chicago: American Library Association, 1995).

3. Carlen Ruschoff, "Cataloging's Prospects: Responding to Austerity with Innovation," Journal of Academic Librarianship 21, no. 1 (1995): 51-57.

4. Ibid., 55.

5. Daniel CannCasciato, "Tepid Water for Everyone?: The Future OLUC, Catalogers, and Outsourcing," OCLC Systems and Services 10, no. 1 (1994): 5-8. 

73-77.

6. Rick J. Block, "Cataloging Outsourcing: Issues and Options," Serials Review (fall 1994):

7. Ibid., 74 .

8. Clare B. Dunkle, "Outsourcing the Catalog Department: A Meditation Inspired by the Business and Library Literature," Journal of Academic Librarianship 22, no. 1 (1996): 33-43.

9. Ibid., 42.

10. Magda El-Sherbini and Mary Harris, "Cataloging Alternatives: An Investigation of Contract Cataloging, Cooperative Cataloging, and the Use of Temporary Help," Cataloging \& Classification Quarterly 15, no. 4 (1992): 67-88.

11. Ibid., 85-86.

12. Cynthia Whitacre, "OCLC's TECHPRO Service," Serials Review (fall 1994): 77-78.

13. Ibid., 78.

14. Jim Dwyer, "From PromptCat to Recat, or, you Only Catalog Twice," Technicalities 15 (May 1995): 4.

15. Ibid., 4.

16. Cynthia Whitacre, "Record Selection Quality From the Perspective of an Outsourcing Vendor" (paper presented at an ALCTS CCS Copy Cataloging Discussion Group at the Midwinter Meeting of the American Library Association, Washington, D.C., January 1997).

17. David Griffin, "The WLN Cataloging Service and the Cataloging of Serials," Advances in Serials Management 3 (1989): 213-232.

18. Gary M. Shirk, "Outsourced Library Technical Services: The Bookseller's Perspective," Library Acquisitions: Practice \& Theory 18, no. 4 (1994): 383-395.

19. Ibid., 388.

20. Carmel C. Bush, Margo Sasse, and Patricia Smith, "Toward a New World Order: A Survey of Outsourcing Capabilities of Vendors for Acquisitions, Cataloging and Collection Development Services," Library Acquisitions: Practice \& Theory 18, no. 4 (1994): 397-416.

21. Karen Wilhoit, "Outsourcing Cataloging at Wright State University," Serials Review (fall 1994): 70-73.

22. Barbara A. Winters, "Cataloging Outsourcing at Wright State University: Implications for Acquisitions Managers," Library Acquisitions: Practice E Theory 18, no. 4 (1994): 367-373.

23. Wilson, "Outsourcing Copy Cataloging," 359-383.

24. Colleen F. Hyslop, "Using PromptCat to Eliminate Work: MSU's Experience," Library Acquisitions: Practice \& Theory 19, no. 3 (1995): 359-362.

25. Ibid., 361.

26. Magda El-Sherbini, "Contract Cataloging: A Pilot Project for Outsourcing Slavic Books," Cataloging E Classification Quarterly 20, no. 3 (1995): 57-73.

27. Ibid., 66-67.

28. Laura Tull, "Contract Cataloging: Retrospective Conversion of a Technical Report Collection," Technical Services Quarterly 9, no. 1 (1991): 3-15.

29. Ibid., 14-15.

30. Karen Dornseif, “Outsourcing Cataloging: An Alternative for Small Libraries," Colorado Libraries 21 (spring 1995): 48-49.

31. Ibid., 49.

32. Karen A. Wilson, "Vendor-Supplied Cataloging and Contract Cataloging Services: A

Report of the ALCTS Creative Ideas in Technical Services Discussion Group, American Library Association, Midwinter Meeting, Los Angeles, February 1994," Technical Services Quarterly 12, no. 2 (1991): 60-63.

33. Ibid., 61-62.

34. American Library Directory, 49th ed. (New York: R.R. Bowker, 1996). 